\title{
Stabilization of Cytokinin Levels Enhances Arabidopsis Resistance Against Verticillium longisporum
}

\author{
Michael Reusche, ${ }^{1}$ Jana Klásková, ${ }^{2}$ Karin Thole, ${ }^{1}$ Jekaterina Truskina, ${ }^{1}$ Ondřej Novák, ${ }^{3}$ Dennis Janz, ${ }^{4}$ \\ Miroslav Strnad, ${ }^{2,3}$ Lukáš Spíchal, ${ }^{2}$ Volker Lipka, ${ }^{1}$ and Thomas Teichmann ${ }^{1}$ \\ ${ }^{1}$ Plant Cell Biology, Albrecht-von-Haller-Institute, Georg-August-University Göttingen, Julia-Lermontowa-Weg 3, D-37077 \\ Göttingen, Germany; ${ }^{2}$ Centre of the Region Haná for Biotechnological and Agricultural Research, Faculty of Science, \\ Palacký University, Šlechtitelů 11, CZ-78371 Olomouc, Czech Republic; ${ }^{3}$ Laboratory of Growth Regulators, Palacký \\ University \& Institute of Experimental Botany AS CR, Šlechtitelů 11 CZ-78371 Olomouc, Czech Republic; ${ }^{4}$ Forest Botany \\ and Tree Physiology, Büsgen-Institute, Georg-August-University, Büsgenweg 2, D-37077 Göttingen, Germany
}

Submitted 12 December 2012. Accepted 2 April 2013.

\begin{abstract}
Verticillium longisporum is a vascular pathogen that infects the Brassicaceae host plants Arabidopsis thaliana and Brassica napus. The soilborne fungus enters the plant via the roots and colonizes the xylem of roots, stems, and leaves. During late stages of infections, Verticillium spp. spread into senescing tissue and switch from biotrophic to a necrotrophic life style. Typical symptoms of $V$. longisporuminduced disease are stunted growth and leaf chlorosis. Expression analyses of the senescence marker genes $S E N E S$ CENCE-ASSOCIATED GENE12, SENESCENCE-ASSOCI$A T E D G E N E 13$, and WRKY53 revealed that the observed chlorosis is a consequence of premature senescence triggered by Verticillium infection. Our analyses show that, concomitant with the development of chlorosis, levels of trans-zeatin decrease in infected plants. Potentially, induction of cytokinin oxidase/dehydrogenase expression by Verticillium infection contributes to the observed decreases in cytokinin levels. Stabilization of Arabidopsis cytokinin levels by both pharmacological and genetic approaches inhibits Verticillium proliferation and coincides with reduced disease symptom development. In summary, our results indicate that $V$. longisporum triggers premature plant senescence for efficient host plant colonization.
\end{abstract}

Fungi of the genus Verticillium are soilborne, vascular plant pathogens causing crop failures in cold (Pegg and Brady 2002) and subtropical climates (Fradin and Thomma 2006). The associated plant disease is generally known as Verticillium wilt. The genus Verticillium subdivides into five species (Barbara and Clewes 2003; Inderbitzin et al. 2011; Karapapa et al. 1997; Pegg and Brady 2002), of which Verticillium dahliae, V. alboatrum, and $V$. longisporum are economically important plant pathogens. $V$. dahliae covers a broad host spectrum with more than 200 plant species of different plant genera (Agrios 1997; Snyder and Smith 1981), in striking contrast to V. longisporum specifically infecting members of family Brassicaceae.

Corresponding authors: T. Teichmann; Telephone: +1 0049-551-39177802; Fax: +1 0049-551-39177809; E-mail: tteichm@gwdg.de; and V. Lipka; Telephone: +1 0049-551-39-177801; Fax: +1 0049-551-39177809; E-mail: vlipka@gwdg.de

* The $\boldsymbol{e}$-Xtra logo stands for "electronic extra" and indicates that seven supplementary figures are published online.

(C) 2013 The American Phytopathological Society
Recent phylogenetic analyses suggest that the amphidiploid species $V$. longisporum originated from hybridization events between haploid $V$. dahliae lineages and an unknown parental line (Inderbitzin et al. 2011; Karapapa et al. 1997; Klosterman et al. 2009).

Verticillium spp. infect their hosts via the root (Eynck et al. 2007) and colonize the plant vascular system. After reaching aerial parts of the plant, the fungus leaves the xylem and invades leaf tissue, switching from biotrophy to a necrotrophic life style. Symptoms caused by Verticillium infections under controlled conditions in the lab are stunted growth, early flowering, and chlorosis.

Leaf chlorosis may be the result of toxins secreted by the fungus or, alternatively, indicate an induced early senescence of host plants. Early senescence of infected plants has been reported for several host-pathogen interactions, and it was hypothesized that pathogens may induce senescence as a part of their infection strategy (Swartzberg et al. 2008; Thatcher et al. 2009). Usually, in noninfected plants, senescence is an orderly, controlled process with the aim to conserve nutrients by redistributing them from aging source organs to vital sink organs. Possibly, pathogens take advantage of senescence to increase the availability of nutrients. The first visible indicator of leaf senescence is breakdown of chloroplasts. On the molecular level, inductions of SENESCENCE-ASSOCIATED GENES $(S A G)$ are the hallmark of senescence (Buchanan-Wollaston et al. 2005; van der Graaff et al. 2006). For example, SAG12, encoding a cysteine protease, is a well-described $S A G$, exclusively turned on during senescence, and has been used as a molecular marker of senescence (De Michele et al. 2009; Noh and Amasino 1999; Pontier et al. 1999).

A key hormone involved in the control of senescence is cytokinin (Hwang et al. 2012; Lim et al. 2007). Starvation of leaves induced by detachment or dark treatment induces senescence (Buchanan-Wollaston et al. 2005; Dietrich et al. 2011; Richmond and Lang 1957). Activation of the senescence program can be delayed by exogenous application of cytokinin or by autoregulated cytokinin biosynthesis in transgenic plants expressing the cytokinin biosynthesis gene IPT from Agrobacterium tumefaciens under the control of the SAG12 promoter (Calderini et al. 2007; Chen et al. 2001; Gan and Amasino 1995; Huynh et al. 2005; Richmond and Lang 1957; Sykorova et al. 2008; Xu et al. 2009).

Naturally occurring cytokinins are derivates of adenine, carrying an isoprenoid or aromatic side chain at the $\mathrm{N}^{6}$ position. The most prevalent cytokinins in Arabidopsis are zeatin-derived 
cytokinins (e.g., trans-zeatin $[t Z]$ ), while isopentenyladenine (iP) occurs at lower concentrations (Werner et al. 2003).

The plant cytokinin pool is regulated by cytokinin biosynthesis, conjugation, and degradation (Mok and Mok 2001). $N$ glycosylation catalyzed by $\mathrm{N}$-glycosyltransferases irreversibly inactivates cytokinins (Hou et al. 2004). In contrast, cleavage of $O$-glycosylated $t Z$ by a $\beta$-glucosidase (GUS) results in the release of active $t Z$ (Brzobohaty et al. 1993; Falk and Rask 1995).

Cytokinin degradation is mediated by cytokinin oxidases/ dehydrogenases (CKX), belonging to a class of FAD-dependent oxidoreductases (Galuszka et al. 2007; Paces et al. 1971; Whitty and Hall 1974) that catalyze the oxidation of cytokinin to an imine intermediate that hydrolyses to adenine and unsaturated aldehyde (Brownlee et al. 1975; Popelkova et al. 2006). The Arabidopsis genome encodes seven CKX isoforms (Bilyeu et al. 2001; Werner et al. 2001) with specificity for certain cytokinins (Hare and Vanstaden 1994; Schmülling et al. 2003). Whereas AtCKX2 and AtCKX4 have been shown to preferentially cleave $t \mathrm{Z}$ and, to a lesser extent, iP free bases, AtCKX1, AtCKX3, and AtCKX7 recognize also their ribosides, ribotides, or even the 9-glucoside (Galuszka et al. 2007; Kowalska et al. 2010). Interestingly, AtCKX1 and AtCKX7 deactivate more effectively cis-zeatin $(c \mathrm{Z})$ than $t \mathrm{Z}$ (Gajdosova et al. 2011).

For many plant-pathogen interactions, changes in cytokinin contents and cytokinin signaling have been reported (Choi et al. 2011). Biotrophic pathogens produce cytokinins and cytokinin-derivatives (Jameson 2000; Pertry et al. 2010) or increase plant sensitivity to cytokinins (Pertry et al. 2009) to influence host plant physiology. Biotrophic pathogens may benefit from the cytokinin-mediated increase of sink strength that improves nutrient supply in infected leaf areas (Walters and McRoberts 2006). In contrast, cytokinins that are plant derived contribute to plant immune responses. Arabidopsis plants with elevated cytokinin levels show increased defense responses against the hemibiotrophic bacterium Pseudomonas syringae pv. tomato DC3000 through cross-talk of cytokinin with salicylic acid (SA) signaling (Choi et al. 2010). The bZIP transcription factor TGA3 controls expression of the SA-regulated defense gene PATHOGENESIS RELATED PROTEIN1 (PRI). Cytokinin activates the ARABIDOPSIS RESPONSE REGULATOR2 (ARR2) by phosphorylation, and cooperativity of TGA3 and ARR2 at the $P R 1$ promoter results in high $P R 1$ expression (Choi et al. 2010). However, the mechanisms of cytokinin-mediated increase of resistance against pathogens differ considerably between host plants. In tobacco, cytokinin treatment inhibits Pseudomonas syringae pv. tabaci in planta proliferation by SA-independent induction of phytoalexin biosynthesis (Grosskinsky et al. 2011).

Investigations of the role of cytokinins in the interaction of plants with pathogens that kill their host indicate that low cytokinin levels may be beneficial for the necrotrophic life style of plant pathogens. The necrotrophic pathogens Botrytis cinerea and Penicillium expansum do not produce cytokinins (Murphy et al. 1997), and Arabidopsis plants with decreased cytokinin contents are more susceptible to infection with the necrotrophic fungus Alternaria brassicicola (Choi et al. 2010). Artificial increases of cytokinin concentrations alleviate symptom development and reduce fungal proliferation in plants infected with B. cinerea (Swartzberg et al. 2008).

We monitored changes of plant cytokinin content in the Arabidopsis thaliana-V. longisporum pathosystem and observed a decrease in cytokinin levels before the appearance of leaf chlorosis. Early senescence triggered by decreases in cytokinin contents may be an integral part of the necrotrophic phase of the Verticillium infection process. To test this hypothesis, we investigated the effect of artificial cytokinin increases on pathogen-induced symptom development and fungal proliferation. Our results suggest that $V$. longisporum actively induces senescence, allowing an efficient colonization of leaves during the necrotrophic phase.

\section{RESULTS}

\section{$t Z$ concentrations are decreased}

in Verticillium-infected Arabidopsis.

To analyze the time course of symptom development during Verticillium infection of Arabidopsis, we root-dip inoculated Arabidopsis Columbia (Col-0) seedlings with V. longisporum strain VL43 and monitored the infection process between 14 and 28 days after inoculation (dai). Symptom development was studied by quantification of leaf area reduction (stunting) and visual recording of leaf chlorosis. In planta proliferation of $V$. longisporum was quantified by determination of fungal DNA using real-time polymerase chain reaction (PCR). From 14 dai, infected plants showed stunting and beginning of leaf curling (Fig. 1A and B). At 21 dai, infected plants were significantly stunted compared with controls and first chlorotic leaves could be seen. Severe stunting and chlorosis of infected plants was observed at 28 dai, with some infected leaves showing necrosis, whereas control plants appeared vital with green leaves (Fig. 1A and B). Fungal DNA could be detected in rosette leaves concomitant with the appearance of disease symptoms on aerial plant parts. The successful fungal proliferation during the time course of infection is reflected by the increasing amounts of fungal DNA (Fig. 1C). At 28 dai, VL43 massively colonized necrotic leaf material whereas fungal DNA content in green and chlorotic leaves was significantly lower (Supplementary Fig. S1). The early appearance of leaf chlorosis indicates that VL43 infection may trigger premature senescence. To confirm the pathogen-induced onset of senescence, we performed expression analyses of the senescence marker genes $S A G 12, S A G 13$, and WRKY53 (Gan and Amasino 1995, 1997; Miao et al. 2004; Pegadaraju et al. 2005; Yoshida 2003). Real-time PCR analyses of noninfected control and Verticillium-infected plants harvested at 14, 21, and 28 dai revealed induction of all three SAG in infected plants (Fig. 2A to C). SAG12 and SAG13 were upregulated throughout the whole time course, while WRKY53 showed a transient induction. Because senescence often correlates with decreases in cytokinin concentrations (Buchanan-Wollaston et al. 2005; Lim et al. 2007), we measured levels of cytokinin free bases and their metabolites by liquid chromatography (LC) mass spectrometry in infected and noninfected plants. The level of $t Z$ free base was decreased in infected plants at 14 and 21 dai compared with noninfected controls (Fig. 2D). At 28 dai, we observed an age-dependent decrease of $t Z$ levels also in the controls. At this time point, Verticillium infection did not reduce $t Z$ levels further. During the course of infection, the concentrations of other isoprenoid free cytokinin bases ( $c Z$, iP, and dihydrozeatin [DHZ]) were not changed. Also, concentrations of $t$ Z-glucosides and biosynthetic precursors were not altered in infected plants (Supplementary Fig. S2). Together, these results indicate that changes of cytokinin conjugation or a decrease of biosynthesis cannot be reasons for lower cytokinin concentrations in Verticillium-infected plants. The overall pathogen-induced reductions of cytokinins were corroborated by analyses of the established cytokinin marker line Arabidopsis Wassilewskija (WS) ARR $5_{p r o}$ :GUS (D'Agostino et al. 2000; Kudryakova et al. 2008). The WS ecotype showed VL43-induced stunting comparable with Col-0 plants. The $A R R 5_{p r o}: G U S$ activity was consistently lower in VL43-infected plants compared with 
noninfected control plants (Supplementary Fig. S3). Taken together, these data indicate that Verticillium infection is accompanied by a significant drop in cytokinin concentrations of Arabidopsis leaves which might result from enhanced cytokinin degradation.

\section{Verticillium infection induces expression of specific CKX genes.}

We hypothesized that increased expression of $C K X$ genes during Verticillium infection diminishes the cytokinin pool by cytokinin degradation. To analyze a putative role of CKX in VL43induced cytokinin decreases, we determined transcript levels of the seven Arabidopsis $C K X$ genes in infected and noninfected control plants. Expression analyses by real-time PCR revealed that specific CKX isoforms were significantly induced by Verticillium infection at 21 dai (Fig. $3 \mathrm{~A}$ to $\mathrm{C}$ ). $C K X 1$ and $C K X 3$ had a fourfold and eightfold higher transcript level, respectively, at 21 dai. $C K X 2$ showed a 36 -fold increase in transcript abundance at that time point. At 28 dai exclusively, CKX2 exhibited a further increase in transcript levels. In contrast, $C K X 4, C K X 5, C K X 6$, and $C K X 7$ showed no significant differences compared with the controls (Supplementary Fig. S4). Thus, pathogen-induced decreases of cytokinin at 21 dai correlate with the expression profiles of $C K X 1, C K X 2$, and $C K X 3$, and their increased expression rates may be one factor that contributes to cytokinin decreases during Verticillium infections.

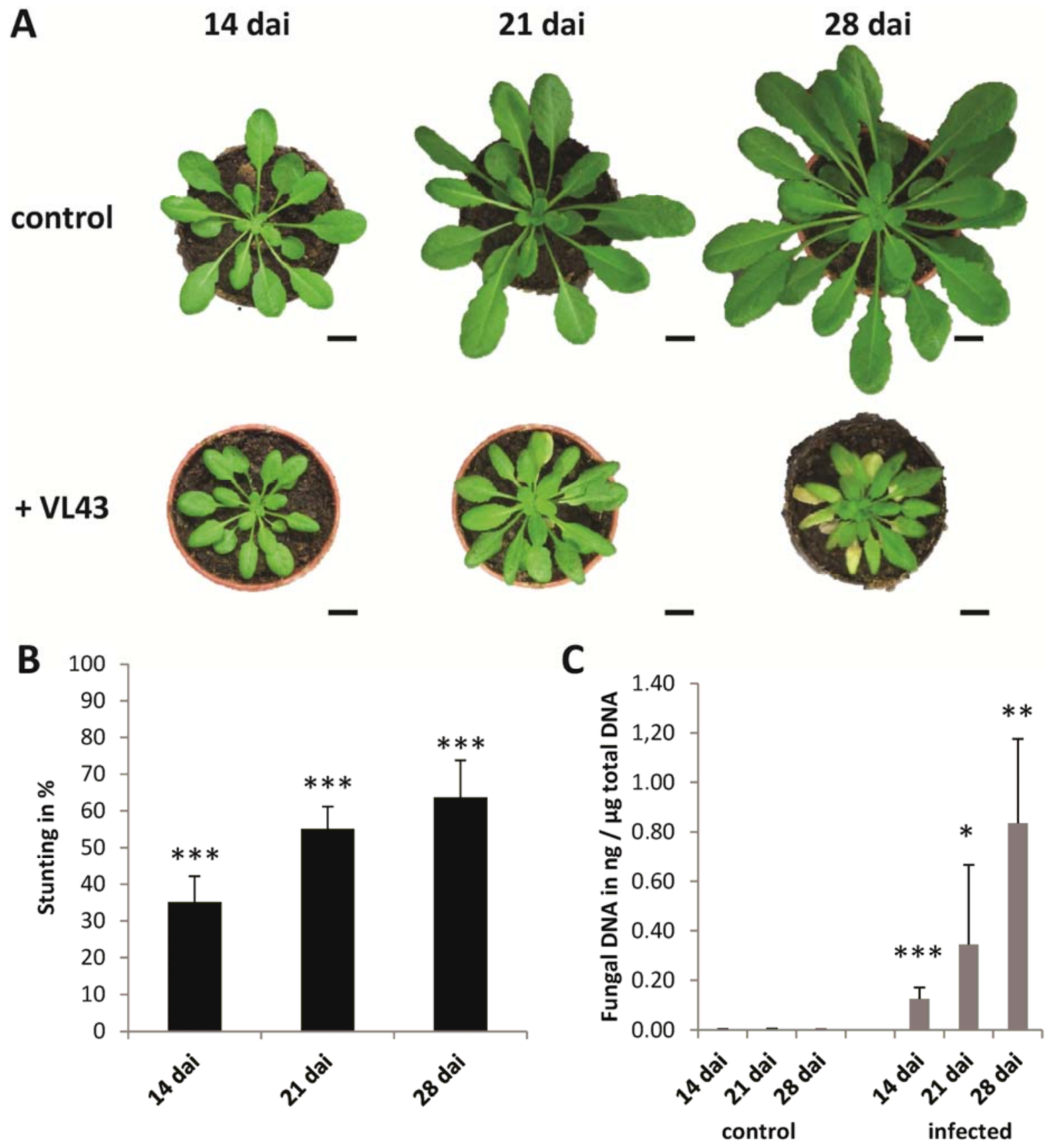

Fig. 1. Symptom development of Arabidopsis Columbia (Col-0) plants after Verticillium longisporum VL43 infection. A, Phenotypes of noninfected control and infected Col-0 plants were monitored between 14 and 28 days after inoculation (dai). Scale bar: $1 \mathrm{~cm}$. B, Stunting of VL43-infected Col-0 plants. Leaf area of noninfected controls was set to $100 \%$ and stunting is shown as percentage of leaf area reduction relative to controls. Data represent means \pm standard deviation (SD) ( $n=10$ plants were analyzed per time point, the experiment was repeated three times, and representative data are shown). C, Quantification of fungal DNA in infected plants; data represent means \pm SD $(n=5$ plants were analyzed per time point, the experiment was repeated three times, and representative data are shown). Significant differences between noninfected and infected plants at $P \leq 0.05,0.01$, and 0.001 are indicated by *,**, and ***, respectively. 
Exogenous application of a synthetic cytokinin reduces Verticillium-induced symptom development and fungal proliferation.

We hypothesized that VL43-induced decreases of plant cytokinin concentrations trigger early senescence, allowing efficient colonization of host plants. To investigate the role of cytokinin decreases during Verticillium infection, we prevented the pathogen-induced decline of cytokinin levels by exogenous application of the synthetic cytokinin 6-benzylaminopurine (BAP). BAP is an aromatic cytokinin that is degraded by CKX with much lower reaction rates than isoprenoid cytokinins (Frebortova et al. 2004; Galuszka et al. 2007). Three days after inoculation of Arabidopsis with Verticillium spp., infected plants and control plants were sprayed with a $50-\mu \mathrm{M}$ BAP solution. The treatment was repeated every third day and continued until 21 dai.

Although exogenous application of BAP caused a general decrease in leaf area of both infected and noninfected plants, it drastically reduced Verticillium-induced symptom development. At 28 dai, non-BAP-treated, infected plants showed considerable stunting, curled leaves, and early senescence, whereas BAP-treated infected plants exhibited less stunting and leaf curling and a significantly lower number of chlorotic and necrotic leaves $(P \leq 0.001)$ (Fig. 4A, C, and D). Fungal prolifera-

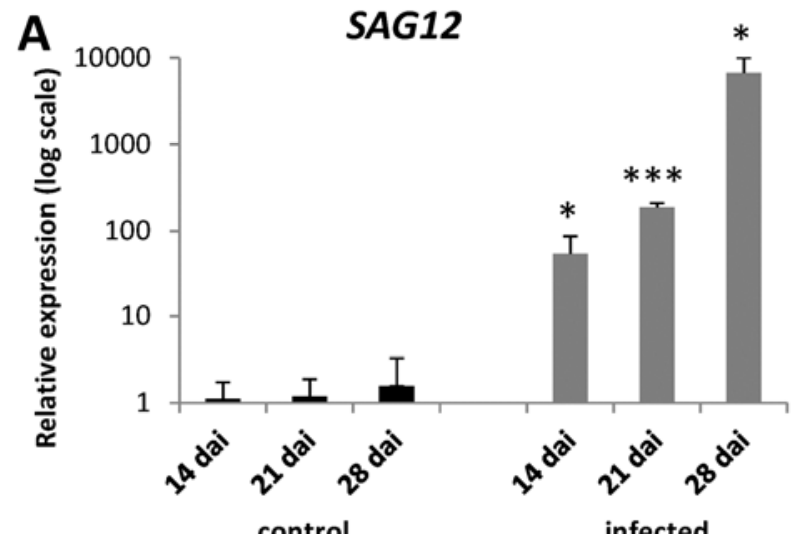

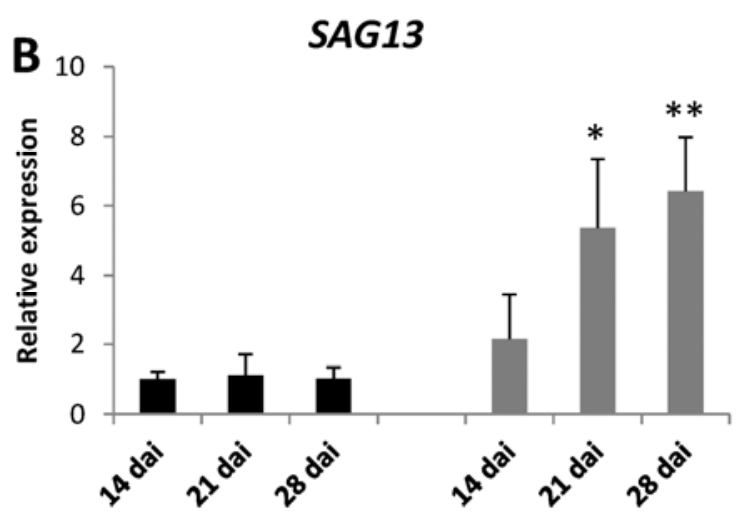

control

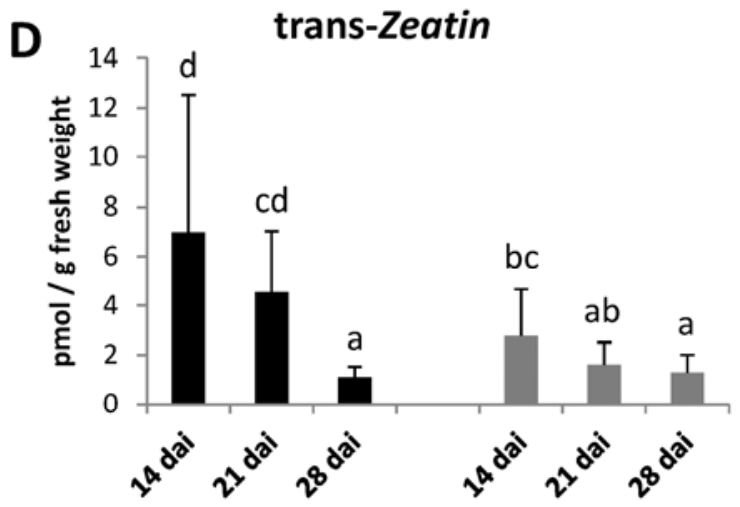

control

infected

Fig. 2. Verticillium longisporum VL43 infection induces gene expression of senescence marker genes and reduces trans-zeatin ( $t \mathrm{Z})$ levels in Arabidopsis Columbia (Col-0) plants. Whole rosettes of A. thaliana (Col-0) were used for analyses. A to C, Real-time expression analyses of SAG12, SAG13, and WRKY53 in noninfected control and infected plants. Data represent means \pm standard deviation (SD) $(n=3$ pools of three plants were analyzed per time point, the experiment was repeated three times, and representative data are shown). Significant differences between noninfected and infected plants at $P \leq 0.05,0.01$, and 0.001 are indicated by $*, * *$, and $* * *$, respectively. D, Quantification of trans-zeatin levels in noninfected control and infected plants. Homogenous subsets are based on an analysis of variance followed by a post-hoc test (Tukey's honestly significant difference) at $P \leq 0.05$. Data represent means \pm SD $(n=11$ pools of three plants).
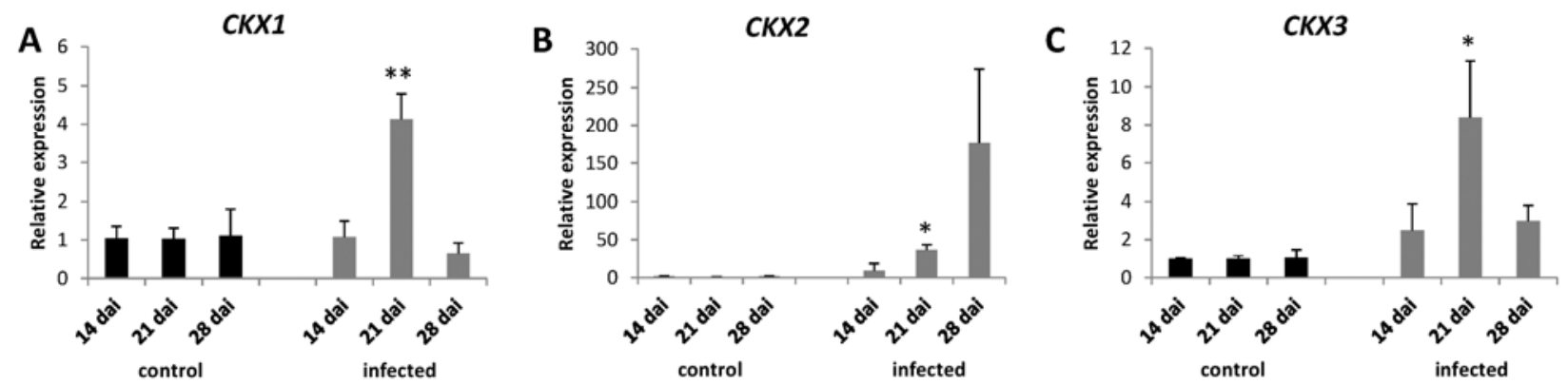

Fig. 3. Verticillium longisporum VL43 infection induces expression of $C K X$ genes in Arabidopsis Columbia (Col-0) plants. Whole rosettes of A. thaliana (Col-0) were used for analyses. A to C, Real-time expression analyses of $C K X 1, C K X 2$, and $C K X 3$ in noninfected control and infected plants. Data represent means \pm standard deviation $(n=3$ pools of three plants were analyzed per time point, the experiment was repeated three times, and representative data are shown). Significant differences between noninfected and infected plants at $P \leq 0.05$ and 0.01 are indicated by $*$ and $* *$, respectively. 
tion in infected plants was monitored by quantitative measurement of $V$. longisporum genomic DNA using real-time PCR. BAP-treated infected plants contained significantly less Verticillium DNA at 28 dai $(P \leq 0.01)$ than nontreated infected plants, indicating that stabilization of cytokinin levels inhibited fungal proliferation (Fig. 4B). Comparative analyses of $V$. longisporum growth rates on medium supplemented with BAP and control medium showed that the observed inhibition of fungal proliferation in planta is not caused by toxic effects of the synthetic cytokinin (Supplementary Fig. S5A to C).

Verticillium-induced symptom development and fungal proliferation can be reduced by inhibition of CKX activity.

To analyze the contribution of CKX to VL43-induced cytokinin degradation, we decided to characterize plants with decreased CKX activity. However, due to the redundancy of $C K X$ genes in the Arabidopsis genome, single knock outs of $C K X$ genes may show no phenotype (Bartrina et al. 2011). Therefore, we used the adenine derivate 2-chloro-6-(3-methoxyphenylamino)-purine (inhibitor of cytokinin degradation [INCYDE]) that inhibits CKX activity and, thus, allows selective investigation of effects during suppressed cytokinin degradation (Zatloukal et al. 2008). Plants were treated with $10 \mu \mathrm{M}$
INCYDE in the same experimental set-up as with BAP. Similar to BAP treatment, INCYDE application generally caused a decrease in leaf area of both infected and noninfected plants (Fig. 5A). However, INCYDE-treated infected plants showed considerably less stunting compared with nontreated infected plants (Fig. 5A and C). Verticillium-induced chlorosis, necrosis, and fungal proliferation were significantly reduced by INCYDE, comparable with the effects of BAP treatment; however, in the case of INCYDE, the protective effect was obtained with a five times lower concentration (Fig. 5B to D). In a growth assay on petri dishes, INCYDE did not directly affect fungal growth.

In summary, the data obtained from pharmacological treatments indicate that stabilization of cytokinin levels in infected plants reduced symptom development and negatively affect fungal proliferation in the host plant.

\section{Transgenic $S A G 12_{\text {pro }}: I P T$ plants are less susceptible to Verticillium infection.}

To corroborate results obtained by pharmacological treatments with BAP and INCYDE, we studied the susceptibility of transgenic $S A G 12_{\text {pro }}$ IPT plants to Verticillium infection. Arabidopsis carrying the construct $S A G 12_{\text {pro }}: I P T$ exhibits an

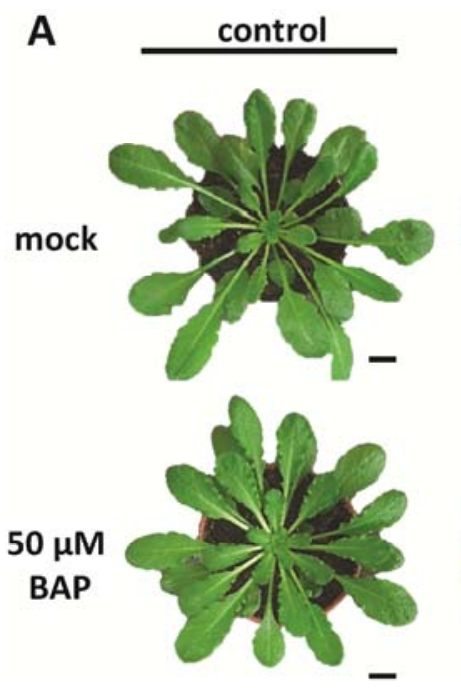

C

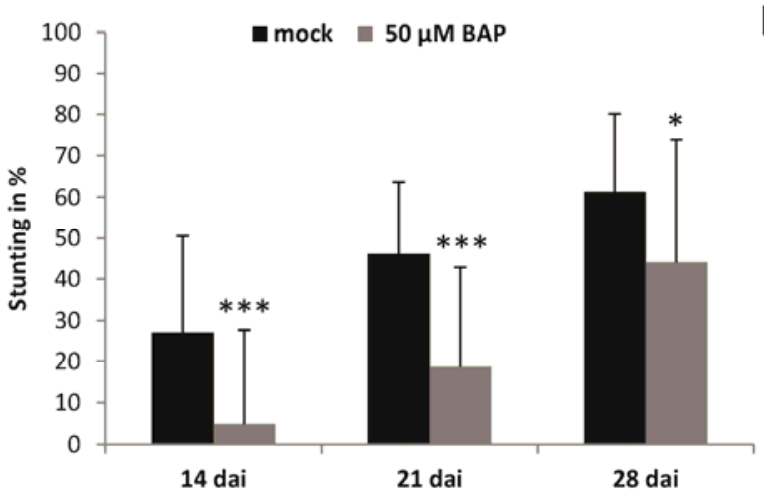

infected
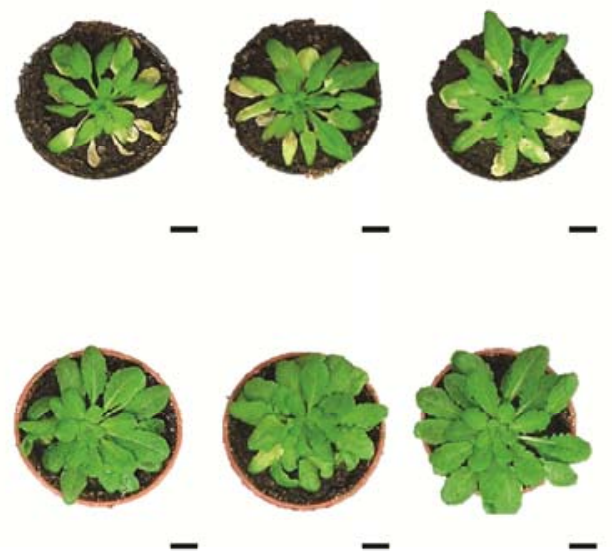

B

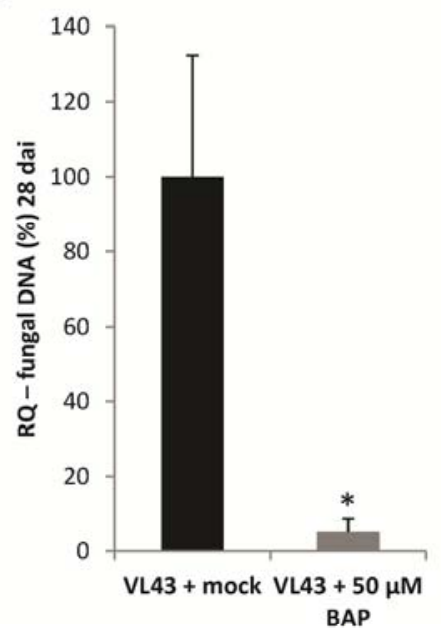

D

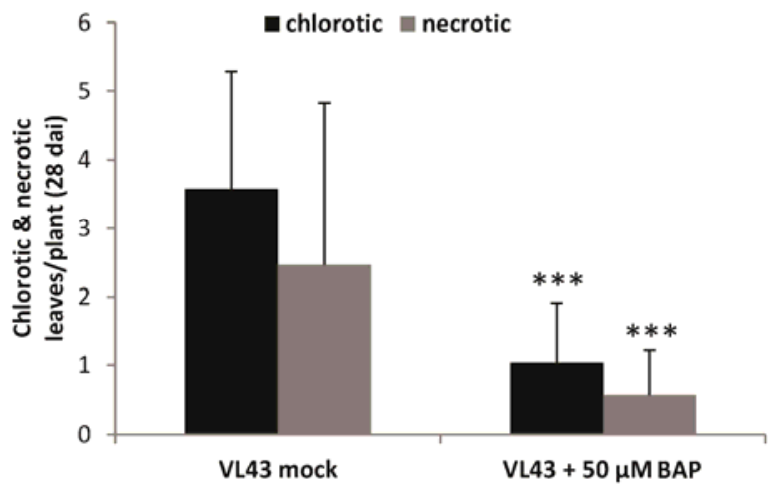

Fig. 4. Application of 6-benzylaminopurine (BAP) reduces symptom development in Verticillium longisporum VL43-infected Arabidopsis Columbia (Col-0) plants. A, Phenotypes of noninfected and infected Col-0 plants at 28 days after inoculation (dai) under mock conditions (treatment with solvent, top row) and after treatment with $50 \mu \mathrm{M}$ BAP (bottom row). Scale bar: $1 \mathrm{~cm}$. B, Relative quantification (RQ) of fungal DNA contents in infected mock- and BAP-treated Col-0 plants at 28 dai by real-time-polymerase chain reaction. VL43 DNA contents of infected mock plants were set to $100 \%$ and VL43 DNA contents of infected BAP-treated plants were calculated as percentage of infected mock plants. Data represent means \pm standard deviation $(\mathrm{SD})(n=3$ pools of three plants were analyzed per time point, experiments were repeated three times, and representative data are shown). C, Stunting of infected mock- and BAPtreated Col-0 plants. Leaf areas of noninfected controls were set to $100 \%$ and stunting is shown as percentage of leaf area reduction relative to noninfected plants. D, Quantification of chlorotic and necrotic leaves of infected mock- and BAP-treated Col-0 plants at 28 dai. C and D, Data represent means \pm SD $(n=$ 15 plants were analyzed per time point, experiments were repeated three times, and representative data are shown). Significant differences between noninfected and infected plants at $P \leq 0.05$ and 0.001 are indicated by $*$ and $* * *$, respectively. 
autoregulated cytokinin biosynthesis induced by senescence (Calderini et al. 2007; Chen et al. 2001; Gan and Amasino 1995; Huynh et al. 2005; Sykorova et al. 2008; Xu et al. 2009). The rational of the experiment is to counteract the pathogeninduced cytokinin degradation by pathogen-induced cytokinin biosynthesis. Analysis of SAG12 expression in Arabidopsis showed that Verticillium infection induced $S A G 12$ transcription beginning at 14 dai (Fig. 2A). Three independent SAG12 pro: IPT Arabidopsis lines were used for analysis. Expression of the Agrobacterium IPT gene was increased in infected plants of two $S A G 12_{\text {pro }}: I P T$ lines at 14 dai and in plants of all three lines starting at 21 dai, whereas $I P T$ expression in noninfected control plants was not detectable (Supplementary Fig. S6). The senescence-induced expression of $I P T$ resulted in a higher $t Z$ level in the infected transgenic line $S A G 12_{\text {pro }}: I P T$ 16-2 if compared with wild-type plants (Fig. 6B). Noninfected $S A G 12_{\text {pro }}$ : $I P T$ did not show phenotypic differences compared with wildtype plants within the time course of the experiment between 14 and 28 dai (Fig. 6A). Analyses of infected wild-type plants and transgenics showed that transgenic plants were less stunted and developed significantly less chlorotic and necrotic leaves (Fig. 6A, C, and D). Quantification of fungal DNA content in infected wild-type and transgenic plants revealed that the reduced symptom development in transgenic plants correlated with a lower amount of fungal DNA in $S A G 12_{\text {pro: }}: I P T$ lines compared with wild-type (Fig. 6E; Supplementary Fig. S7).
Taken together, the comparative analyses of pharmacological treatments affecting cytokinin levels and transgenic plants with pathogen-induced cytokinin biosynthesis indicate that increasing cytokinin levels in Verticillium-infected plants reduced susceptibility to Verticillium infection.

\section{DISCUSSION}

Plant hormones control plant development and responses to biotic and abiotic stresses. To avoid plant defense reactions and to achieve efficient fungal proliferation and accommodation in host plants, pathogens manipulate plant hormone contents or plant hormone signaling (Spichal 2012). Here, we show that Verticillium infection decreases plant cytokinin concentrations and, subsequently, induces premature plant senescence.

\section{$V$. longisporum infection decreases $t Z$ levels and induces the expression of senescence markers in Arabidopsis.}

$V$. dahliae infections of Gossypium hirsutum and Lycopersicon esculentum correlate with reductions in plant cytokinin levels (Misaghi et al. 1972; Patrick et al. 1977). In both V. dahliaehost interactions, decreases in cytokinin levels were observed after the appearance of chlorosis. Patrick and associates (1977) concluded that decreases in cytokinin concentrations are the consequence of diminished plant vitality caused by fungal infec-

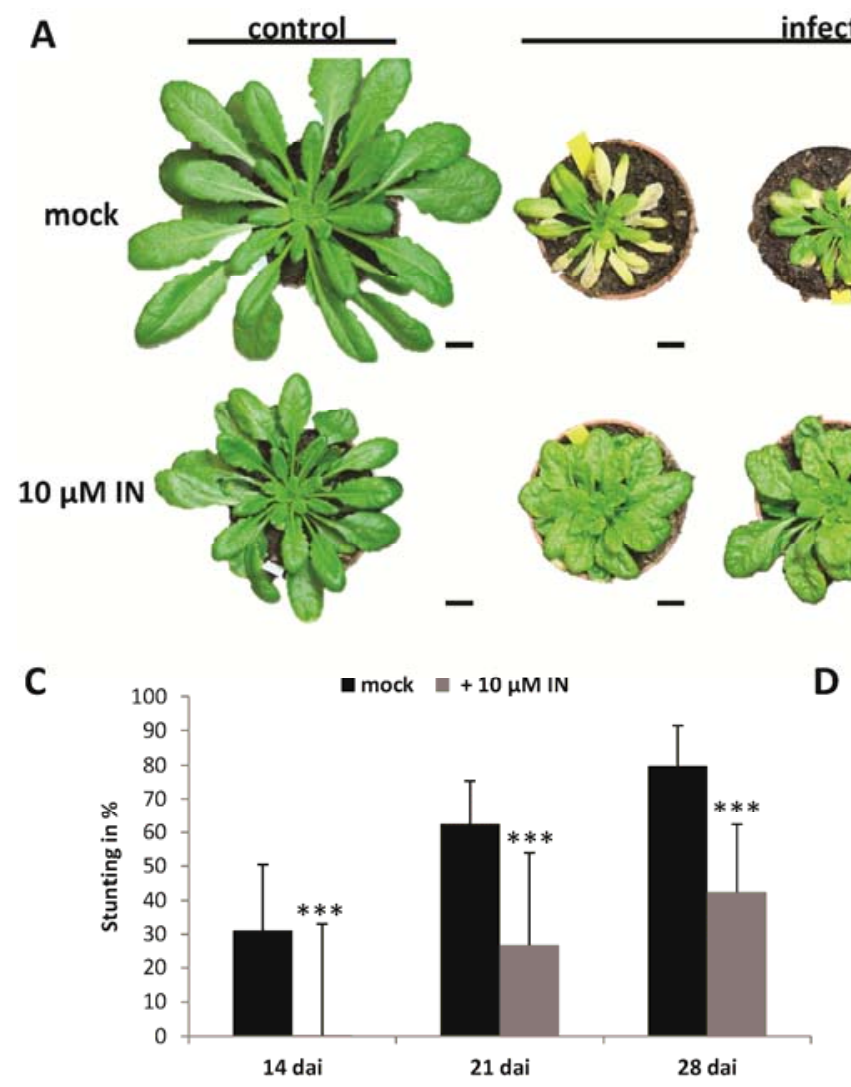

infected B

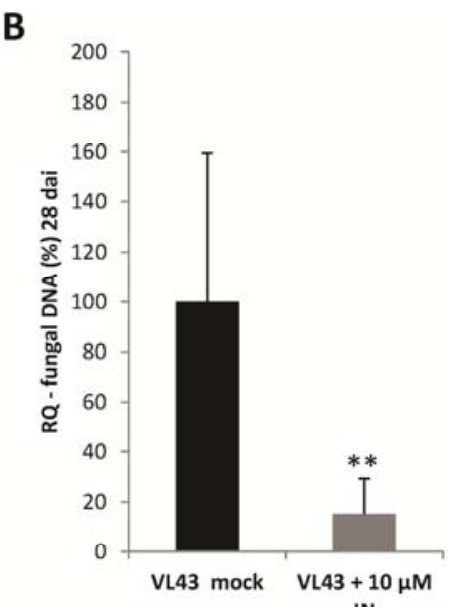

IN

Fig. 5. Application of 2-chloro-6-(3-methoxyphenylamino)purine (INCYDE) reduces symptom development in Verticillium longisporum VL43-infected Arabidopsis Columbia (Col-0) plants. A, Phenotypes of noninfected and infected Col-0 plants at 28 days after inoculation (dai) under mock conditions (treatment with solvent, top row) and after treatment with $10 \mu \mathrm{M}$ INCYDE (10 $\mu \mathrm{M}$ IN, bottom row). Scale bar: $1 \mathrm{~cm}$. B, Relative quantification (RQ) of fungal DNA contents in infected mock- and IN-treated Col-0 plants at 28 dai by real-time-polymerase chain reaction. VL43 DNA contents of infected mock plants were set to $100 \%$ and VL43 DNA contents of infected IN-treated plants were calculated as percentages of infected mock plants. Data represent means \pm standard deviation (SD) $(n=8$ plants were analyzed per time point, experiments were repeated three times, and representative data are shown). $\mathbf{C}$, Stunting of infected mock- and IN-treated Col-0 plants. Leaf area of noninfected controls was set to $100 \%$ and stunting is shown as percentage of leaf area reduction relative to noninfected plants. D, Quantification of chlorotic and necrotic leaves of infected mock- and IN-treated Col-0 plants at 28 dai. Data represent means \pm SD ( $n=15$ plants were analyzed per time point, experiments were repeated three times, and representative data are shown). Significant differences between noninfected and infected plants at $P \leq 0.01$ and 0.001 are indicated by $* *$ and $* * *$, respectively. 
tion. In contrast, our investigations in the pathosystem Arabidopsis-V. longisporum VL43 clearly show decreases of $t \mathrm{Z}$ levels in Arabidopsis leaves before chlorosis become apparent (Figs. $1 \mathrm{~A}$ and 2D). $T \mathrm{Z}$ is one of the prevalent cytokinins in Arabidopsis, showing considerably higher concentrations than $c \mathrm{Z}$, iP, and DHZ (Fig. 2D). Because cytokinin decreases correlate with onset of senescence (Buchanan-Wollaston et al. 2005; Lim et al. 2007), we hypothesized that the observed pathogen-induced decreases of cytokinin levels trigger or accelerate development of early senescence of $V$. longisporum-infected Arabidopsis. During the colonization of Arabidopsis, the hemibiotrophic fungus $V$. longisporum may benefit from senescing plant tissue during its necrotrophic phase in leaves. VL43 induced expression of the senescence marker genes SAG12, SAG13, and WRKY53 (Gan and Amasino 1995, 1997; Miao et al. 2004; Pegadaraju et al. 2005; Yoshida 2003) as early as 14 dai (Fig. 2A to C).The levels of SAG12 and WRKY53 gene induction are similar to levels during natural senescence (Arabidopsis eFP browser) (Schmid et al. 2005; Winter et al. 2007). Thus, expression analyses of senescence marker genes show that $V$. longisporuminduced chlorosis are not the consequence of unspecific damage by fungal toxins but, instead, that a premature plant senescence program is initiated.
The observed pathogen-induced decrease of free $t \mathrm{Z}$ is most likely not caused by increased conjugation of $t Z$, because concentrations of $t \mathrm{Z} \mathrm{N9}$ - and $O$-glucosides did not change during infection. Similarly, concentrations of cytokinin precursors were not lowered by Verticillium infection, indicating that reduction of cytokinin biosynthesis is not the reason for decreases in cytokinin levels. These data support the idea that the observed decreases of $t Z$ cytokinin levels are the consequence of an increased degradation rate.

\section{V. longisporum-infected Arabidopsis exhibits increased expression of the cytokinin oxidase/dehydrogenase genes $C K X 1, C K X 2$, and $C K X 3$.}

The expression profiles of $C K X 1, C K X 2$, and $C K X 3$ during Verticillium infection suggest a role of these enzymes in decreases of cytokinin at 21 dai. However, increased expression of the senescence marker gene $S A G 12$ at 14 dai precedes $C K X$ induction at 21 dai. This suggests that induction of $C K X$ genes is not sufficient to trigger senescence but, instead, may accelerate the development of senescence. Within the Arabidopsis $C K X$ gene family, $C K X 2$ shows the highest induction after infection and the encoded enzyme has a high specificity for $t Z$ (Galuszka et al. 2007). Further research is needed to clarify
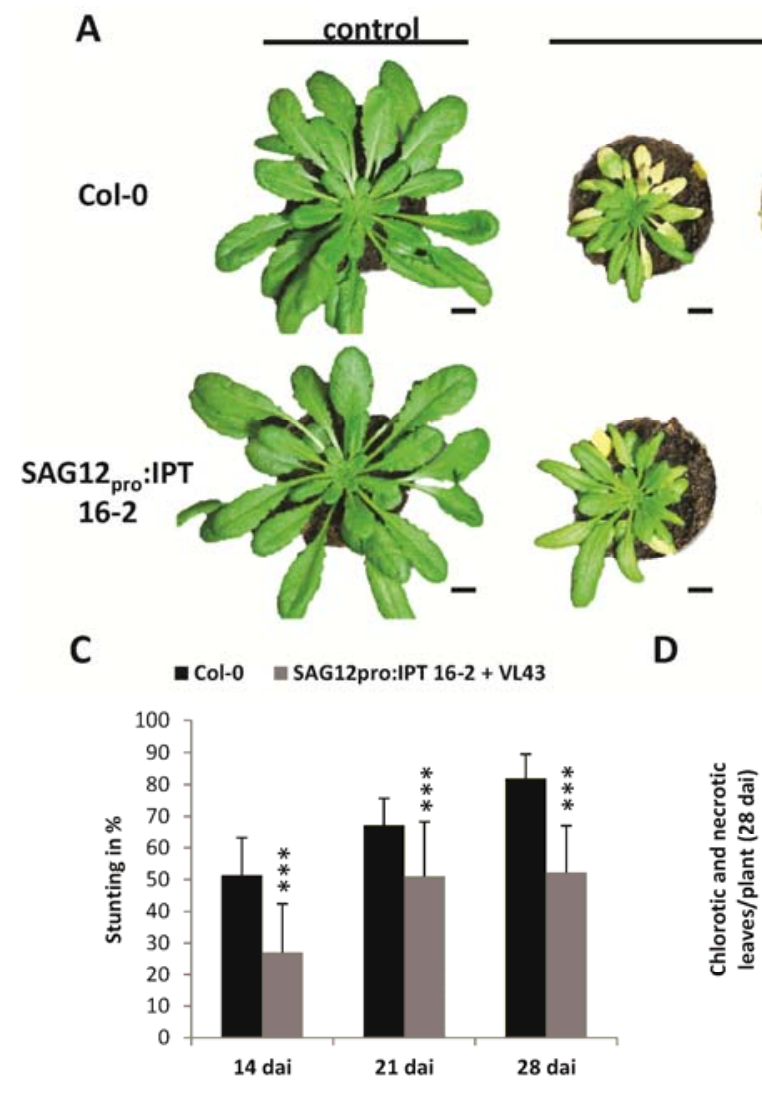

infected

D

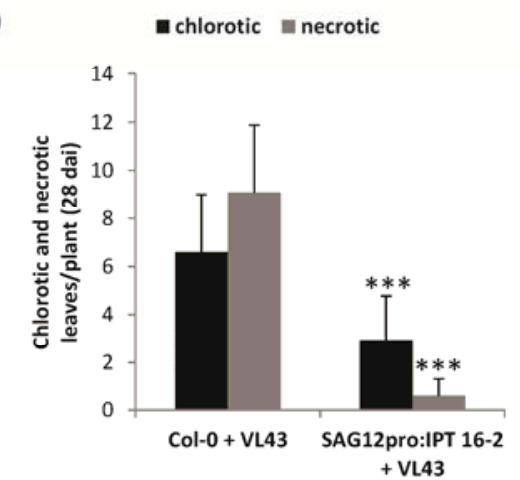

B

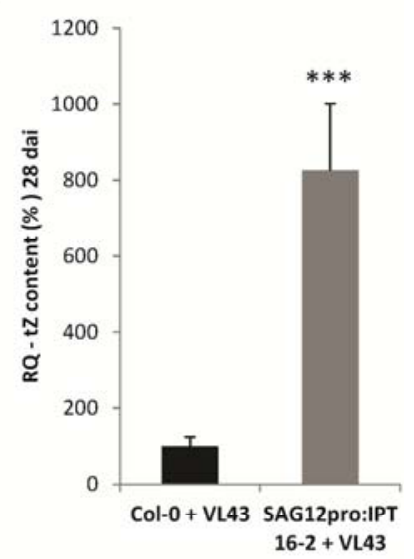

E

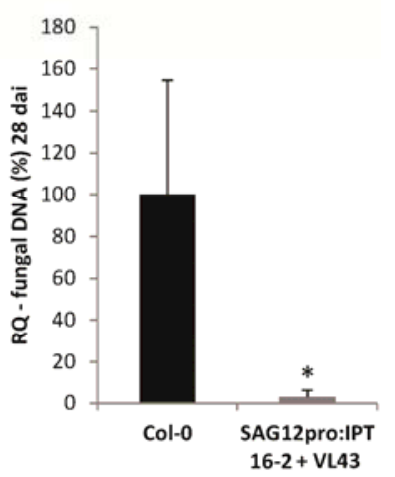

Fig. 6. Transgenic SAG12 $2_{\text {pro }}: I P T$ plants show reduced symptom development after Verticillium longisporum VL43 infection compared with wild-type Arabidopsis Columbia (Col-0) plants. A, Phenotypes of noninfected and infected Col-0 and SAG12 pro:IPT 16-2 plants at 28 days after inoculation (dai). Scale bar: $1 \mathrm{~cm}$. B, Relative quantification (RQ) of trans-zeatin $(t \mathrm{Z})$ contents of infected Col-0 plants compared with $S A G 12_{\text {pro }}: I P T 16-2$ plants at 28 dai. $t$ Z contents of VL43-infected Arabidopsis Col-0 wild-type plants were set to $100 \%$ and $t Z$ contents of VL43-infected transgenic SAG12 pro:IPT plants were calculated as percentage of wild-type plants. Data represent means \pm standard deviation (SD) $(n=5$ plants $)$. C, Stunting of infected Col-0 plants compared with infected transgenic SAG12 pro:IPT 16-2 plants. Leaf area of noninfected controls was set to $100 \%$ and stunting is shown as percentage of leaf area reduction relative to noninfected plants. D, Quantification of chlorotic and necrotic leaves of Col-0 plants compared with SAG12 pro:IPT 16-2 plants at 28 dai. C and D, Data represent means $\pm \mathrm{SD}(n=15$ plants were analyzed per time point, experiments were repeated two times with three independent lines) and representative data are shown. E, RQ of fungal DNA contents of infected Col-0 plants compared with $S A G 12_{\text {pro: }} I P T$ 16-2 plants at 28 dai by real-time-polymerase chain reaction. VL43 contents of infected Arabidopsis Col-0 wild-type plants were set to $100 \%$ and VL43 DNA contents of infected transgenic SAG12 ${ }_{\text {pro }}: I P T$ plants were calculated as percentages of wild-type plants. Data represent means $\pm \mathrm{SD}(n=5$ plants were analyzed per time point, experiments were repeated two times with three independent lines) and representative data are shown. Significant differences between noninfected and infected plants at $P \leq 0.05$ and 0.001 are indicated by $*$ and $* * *$, respectively. 
whether $V$. longisporum specifically targets $C K X 2$ to accelerate senescence development.

To characterize the role of CKX in VL43-induced senescence, we analyzed the symptom development of infected Arabidopsis plants, which exhibit diminished CKX activity. To overcome the redundancy of $C K X$ genes within the Arabidopsis genome (Bartrina et al. 2011), a pharmacological approach employing the CKX inhibitor INCYDE (Zatloukal et al. 2008) was used to achieve CKX activity downregulation. Interestingly, INCYDE application drastically reduced $V$. longisporum induced senescence symptoms (e.g., the number of chlorotic and necrotic leaves in infected plants treated with INCYDE was significantly lower than in untreated controls) (Fig. 5D). This delay in pathogen-induced senescence may be explained by the suppression effect of INCYDE on VL43-induced increases in CKX activity, causing a general increase in cytokinin levels preventing the onset of senescence.

In addition to INCYDE treatment, we used exogenous cytokinin application and a genetic approach to stabilize cytokinin levels during Verticillium infection. Treatment of infected plants with BAP reduced chlorosis and suppressed fungal proliferation similarly to INCYDE treatment (Figs. 4B and D and $5 \mathrm{~B}$ and $\mathrm{D})$. The observed suppression of $V$. longisporum proliferation in Arabidopsis was not caused by a direct, toxic effect of BAP on fungal hyphae but, most probably, by the delay in host plant senescence. In earlier similar experiments, Corsini and associates (1988) could not show an effect of cytokinin treatment on symptom development in $V$. dahliae-infected Solanum tuberosum. The reason for the discrepancy to our studies may be that Corsini and associates (1988) applied BAP only once per week and did tests under less-controlled field conditions. Possibly, the in planta cytokinin concentration was too low or too inconsistent to prevent the onset of pathogeninduced senescence.

As a genetic approach to counteract Verticillium-induced cytokinin decreases, we infected transgenic Arabidopsis expressing the Agrobacterium cytokinin biosynthesis gene IPT under the control of a senescence-induced promoter (Gan and Amasino 1995; Noh and Amasino 1999). In Verticilliuminfected plants, increased expression of the Agrobacterium IPT gene was observable between 14 and 21 dai and resulted in delayed senescence (Fig. 6A and D). This result is in accordance with Swartzberg and associates (2008), who reported reduced symptom development in transgenic $S A G 12_{\text {pro: }}: I P T$ tomato lines infected with the necrotrophic pathogen $B$. cinerea.

In the Arabidopsis-Verticillium pathosystem, SA signaling does not contribute to plant resistance (Ralhan et al. 2012) and, therefore, SA-cytokinin cross-talk (Choi et al. 2010) cannot be the target of Verticillium-induced cytokinin decreases. We propose that $V$. longisporum actively decreases cytokinin levels to trigger early senescence. Senescing tissue may provide easy access to nutrients during the necrotrophic phase of the fungal life cycle. Consequently, artificial increase in cytokinin contents reduces early senescence and inhibits fungal proliferation.

\section{MATERIALS AND METHODS}

\section{Plant material and growth conditions.}

Col- 0 and WS ecotypes of $A$. thaliana were used as the wild type. Seed were sown on soil (Fruhstorfer Erde) and vernalized at $8^{\circ} \mathrm{C}$ overnight, and plants were grown under a photoperiod of $8 \mathrm{~h}$ of light and $16 \mathrm{~h}$ of darkness at 22 and $18^{\circ} \mathrm{C}$, respectively.

\section{Fungal culture.}

V. longisporum isolate VL43 was obtained from A. von Tiedemann at the Plant Pathology Department, University of
Göttingen. A spore suspension $\left(100 \mu \mathrm{l}\right.$ at $1 \times 10^{6}$ spores $\left./ \mathrm{ml}\right)$ was cultivated for one-and-a-half weeks on a rotary shaker at $22^{\circ} \mathrm{C}$ in the dark in $120 \mathrm{ml}$ of potato dextrose broth (PDB) (Sigma, St. Louis), supplemented with Cefotaxime at 0.5 $\mathrm{mg} /$ liter. To initiate sporulation, PDB was exchanged for Czapek-Dox broth (Sigma) supplemented with Cefotaxime at $0.5 \mathrm{mg} /$ liter and cultures were incubated for 1 week. Conidia were harvested by filtration through a folded filter (Schleicher \& Schuell 5951/2, Dassel, Germany) and washed two times with sterile water. Spore concentration was determined with a Thoma-Kammer (Optik-Labor, Lancing, U.K.) and diluted to a concentration of $1 \times 10^{6}$ spores $/ \mathrm{ml}$ for infection.

\section{Inoculation of $A$. thaliana.}

For infection experiments on soil, A. thaliana plants (Col-0 or WS) were grown in a 1:1 sand/soil mixture (number 12262; Vitakraft, Achim, Germany) that was layered on Seramis under a photoperiod of $8 \mathrm{~h}$ of light and $16 \mathrm{~h}$ of darkness at 22 and $18^{\circ} \mathrm{C}$, respectively. Three-and-a-half-week-old plants were incubated for $45 \mathrm{~min}$ in a conidial suspension of VL43 $(1 \times$ $10^{6}$ spores $/ \mathrm{ml}$ ) or mock inoculated in water by dipping. Plants were transplanted into single pots (steam-sterilized soil) and kept under a transparent cover for 4 days to ensure high humidity. To monitor infection, leaf areas of inoculated and control plants were measured at 14, 21, and 28 dai.

\section{Leaf surface measurement.}

Photographs were taken every week $(14,21$, and 28 dai) with a digital camera and analyzed with a custom-made software to quantify the leaf area (Bildanalyseprogramm; Datinf $\mathrm{GmbH}$, Tübingen, Germany). Leaf areas of infected plants were calculated relative to the controls and presented in percent.

\section{Cytokinin measurements.}

For endogenous cytokinin analysis, extraction and purification of approximately $0.2 \mathrm{~g}$ fresh weight was performed according to the method described by Novak and associates (2008). The samples were purified through two ion-exchange chromatography steps (DEAE-Sephadex combined with SPE C18-cartridges) and immunoaffinity purification. The levels of cytokinins were quantified by ultra-performance LC-electrospray tandem mass spectrometry (Novak et al. 2008).

\section{Pharmacological assays.}

Four days after infection, the plants were sprayed every third day with $50 \mu \mathrm{M}$ BAP or with $10 \mu \mathrm{M}$ INCYDE (Zatloukal et al. 2008) until 24 dai. Controls were sprayed with the respective solvent.

\section{Promoter-GUS analyses.}

Whole rosettes of $A R R 5_{\text {pro }}: G U S$ were harvested and plant tissue was ground on ice in a mortar in $700 \mu$ l of extraction buffer. Twelve plants of noninfected control and infected plants were used per time point. Soluble protein was determined by the method of Bradford (Bradford and Williams 1976). Fluorometric assay of GUS activity was performed according to Jefferson and associates (1987) with a Cytofluor fluorescence spectrophotometer at excitation and emission wavelengths of 365 and $455 \mathrm{~nm}$, respectively.

\section{Quantification of $V$. longisporum DNA.}

In planta proliferation of $V$. longisporum VL43 was quantified by determination of fungal DNA using real-time PCR. Whole rosettes of $A$. thaliana (Col-0) were used for analyses. Plant tissue was ground in a mortar under liquid nitrogen and DNA was extracted using the DNeasy plant mini kit (Qiagen, 
Hilden, Germany). The iCycler System (Bio-Rad, Munich) was used for the amplification and quantification of $V$. longisporum DNA using primers OLG70 (5'-CAGCGAAACGCG ATATGTAG-3') and OLG71 (5'-GGCTTGTAGGGGGTTTAG A-3') (Eynck et al. 2007). The amplification mix consisted of $1 \times \mathrm{NH}_{4}$ reaction buffer (Bioline, Taunton, MA, U.S.A.), $3 \mathrm{mM}$ $\mathrm{MgCl}_{2}, 200 \mu \mathrm{M}$ dNTPs, $0.4 \mu \mathrm{M}$ primers, 0.25 units of BIOTaq DNA polymerase (Bioline), $10 \mathrm{nM}$ fluorescein (Bio-Rad), 1:100000 diluted SYBR Green I solution (Cambrex, Charles City, IA, U.S.A.), 20 to $25 \mathrm{ng}$ of template DNA, and doubledistilled water to a total volume of $25 \mu \mathrm{l}$. The PCR program comprised a 2 -min denaturation step at $94^{\circ} \mathrm{C}$ followed by 36 cycles of $20 \mathrm{~s}$ at $94^{\circ} \mathrm{C}, 30 \mathrm{~s}$ at $59^{\circ} \mathrm{C}$, and $40 \mathrm{~s}$ at $72^{\circ} \mathrm{C}$. The amount of $V$. longisporum DNA was determined from a calibration curve established with purified fungal DNA. Fungal DNA contents are shown in nanograms of fungal DNA per microgram of total DNA. In experiments involving pharmacological treatments and transgenic $S A G 12_{\text {pro: }} I P T$ lines, calculations were done according to the $2-\Delta \Delta \mathrm{CT}$ method (Livak and Schmittgen 2001), using UBQ5 as reference. Fungal DNA contents in treated plants and transgenic plants were quantified as percentage of fungal DNA contents in untreated plants and wild-type plants, respectively.

\section{Real-time expression analysis.}

RNA was extracted from $50 \mathrm{mg}$ of leaf material using the innuPREP Plant RNA-Kit (Analytik Jena, Jena, Germany) according to the manufacturer's manual. Whole rosettes of $A$. thaliana (Col-0) were used for analyses. DNA was digested with DNase I, RNase free (Thermo Scientific, Schwerte, Germany). cDNA synthesis from $1 \mu \mathrm{g}$ of total RNA was performed with the RevertAid H Minus First Strand cDNA synthesis kit (Fermentas). The iCycler system (Bio-Rad) was used for amplification and quantification of cDNA using primers designed with a tool from Roche (Basel, Switzerland). The following primers were used: $C K X 1$ (sense $5^{\prime}$-ctgagaagcggaattctgaac-3' and antisense $5^{\prime}$-gagtacctgatccatttaacca-3'), CKX2 (sense $5^{\prime}$ gaggtttgggtcaatttgga- $3^{\prime}$ and antisense $5^{\prime}$-agagcatccgaaaccatttg$\left.3^{\prime}\right), C K X 3$ (sense $5^{\prime}$-tctcaatacacagtcaacgagga- $3^{\prime}$ and antisense $5^{\prime}$-tcgtacataaacctcttacatgg-3'), CKX4 (sense $5^{\prime}$-cccttcccattattg accag- $3^{\prime}$ and antisense $5^{\prime}$-cgaaatacggaacatcttgtacg- $\left.3^{\prime}\right), C K X 5$ (sense $5^{\prime}$-ccatggtcctcaaattagtaacg- $3^{\prime}$ and antisense $5^{\prime}$-tctgagcat ctcatcacctctc- $3^{\prime}$ ), CKX6 (sense $5^{\prime}$-caactggagattgtcacaggaa- $3^{\prime}$ and antisense $5^{\prime}$-cctaaaccaccaagaacacca- $3^{\prime}$ ), $C K X 7$ (sense $5^{\prime}$ caccagagctagggttttgc- $3^{\prime}$ and antisense $5^{\prime}$-catcgaactcggtgtatacta ctctt-3'), SAG12 (sense $5^{\prime}$-gtgtctacgcggatgtgaag- $3^{\prime}$ and antisense $5^{\prime}$-cagcaaactgatttaccgca-3'), SAG13 (sense $5^{\prime}$-aggaaaac tcaacatcctcgtc- $3^{\prime}$ and antisense $5^{\prime}$-gctgactcgagatttgtagcc- $3^{\prime}$ ), WRKY53 (sense $5^{\prime}$-cggaagtccgagaagtgaag- $3^{\prime}$ and antisense $5^{\prime}$ tctgaccactttggtaacatcttt- $3^{\prime}$ ), IPT (sense $5^{\prime}$-acccatggacctgcatcta$3^{\prime}$ and antisense $5^{\prime}$-ggagctcagggctggcgtaacc- $3^{\prime}$ ), and, as reference, UBQ5 (sense $5^{\prime}$-gacgcttcatctcgtcc- $3^{\prime}$ and antisense $5^{\prime}$ gtaaacgtaggtgagtcca- $3^{\prime}$. The amplification mix consisted of $1 \times$ $\mathrm{NH}_{4}$ reaction buffer (Bioline), $2 \mathrm{mM} \mathrm{MgCl} 2,100 \mu \mathrm{M}$ dNTPs, $0.4 \mu \mathrm{M}$ primers, 0.25 units of BIOTaq DNA polymerase (Bioline), $10 \mathrm{nM}$ fluorescein (Bio-Rad), 1:100000 diluted SYBR Green I solution (Cambrex), $1 \mu$ of a 1:10 dilution of cDNA as template, and double-distilled water to a total volume of $25 \mu \mathrm{l}$. The PCR regime consisted of an initial 90-s denaturation step at $95^{\circ} \mathrm{C}$ followed by 40 cycles of $20 \mathrm{~s}$ at $95^{\circ} \mathrm{C}, 20 \mathrm{~s}$ at $55^{\circ} \mathrm{C}$, and $40 \mathrm{~s}$ at $72^{\circ} \mathrm{C}$. Calculations were done according to the 2$\Delta \Delta$ CT method (Livak and Schmittgen 2001).

\section{Construction of $S A G 12_{\text {pro }}: I P T$ vector for plant transformation.}

pSG516 was obtained from R. Amasino, University of Wisconsin, Madison. SAG12 pro:IPT-NOS was excised from pSG516 with SpeI. The resulting 3.2-kb fragment was cloned into the binary vector pCambia2300 using the $X b a I$ restriction site. Transformation of the Agrobacterium strain GV3101 carrying the helper plasmid pMP90 was done by electroporation (MicroPulser; Bio-Rad).

\section{Transformation of Arabidopsis by floral dip.}

The Agrobacterium strain containing the construct $S A G 12_{\text {pro }}: I P T$ was grown on Luria-Bertani plates containing kanamycin at $50 \mathrm{mg} / \mathrm{liter}$, gentamycin at $25 \mathrm{mg} / \mathrm{liter}$, and rifampicin at $100 \mathrm{mg} / \mathrm{liter}$ at $28^{\circ} \mathrm{C}$ for $48 \mathrm{~h}$. A single colony was transferred to $5 \mathrm{ml}$ of double yeast tryptone medium containing the same antibiotics and cultured overnight at $28^{\circ} \mathrm{C}$ with vigorous shaking $(180 \mathrm{rpm})$. The overnight culture was added to $500 \mathrm{ml}$ of the same medium and cultured overnight to an optical density at $600 \mathrm{~nm}$ of 0.5 to 1 . The Agrobacterium cells were harvested by centrifugation for $15 \mathrm{~min}\left(4,000 \mathrm{rpm}, 4^{\circ} \mathrm{C}\right)$ and resuspended in infiltration medium (5.0\% sucrose and $0.05 \%$ Silwet L-77). Transformation of Arabidopsis plants was performed by the floral-dip method (Clough and Bent 1998). Selection of transgenic plants was performed on selective medium containing kanamycin. Transgenic plants were transferred to soil and grown until seed harvest.

\section{Statistical analysis.}

Statistics were evaluated with the GraphPad QuickCalcs $t$ test. For statistical analysis of $t Z$ contents, we fitted a linear model with the logarithmized cytokinin contents as the response variable and treatment (control and inoculated), days after inoculation, and experiment repetition as the explanatory variables. An analysis of variance was used to test for effects of the explanatory variables; because the repetition of the experiment had a significant effect on the response, a linear mixedeffect model was then fitted, again using logarithmized cytokinin contents as the response variable and treatment and days after inoculation as the explanatory variable but applying experiment repetition as the random variable. The model was estimated by residual maximum likelihood (Pinheiro et al., 2013; R package 'nlme', available from the R Project for Statistical Computing software website). A post-hoc test was conducted, using Tukey's honestly significant difference test to calculate significant contrasts between treatments at different time points and to identify homogenous subsets (Hothorn et al. 2008; R package 'multcomp', available from the R Project website). All statistics were conducted in R (The R Project for Statistical Computing software website).

\section{ACKNOWLEDGMENTS}

We are grateful for funding by the Deutsche Forschungsgemeinschaft (DFG FOR-546, "Signals in the Verticillium-plant interaction") and grant number ED0007/01/01 Centre of Region Haná for Biotechnological and Agricultural Research. We thank the Verticillium "Forschergruppe" for valuable comments and suggestions, R. Amasino for providing the pSG516 construct, and J. Pioch for contributing to the project.

\section{LITERATURE CITED}

Agrios, G. N. 1997. Plant Pathology, 4th ed. Academic Press, New York.

Barbara, D. J., and Clewes, E. 2003. Plant pathogenic Verticillium species: How many of them are there? Mol. Plant Pathol. 4:297-305.

Bartrina, I., Otto, E., Strnad, M., Werner, T., and Schmuelling, T. 2011. Cytokinin regulates the activity of reproductive meristems, flower organ size, ovule formation, and thus seed yield in Arabidopsis thaliana. Plant Cell 23:69-80.

Bilyeu, K. D., Cole, J. L., Laskey, J. G., Riekhof, W. R., Esparza, T. J., Kramer, M. D., and Morris, R. O. 2001. Molecular and biochemical characterization of a cytokinin oxidase from maize. Plant Physiol. 125:378-386 
Bradford, M. M., and Williams, W. L. 1976. New, rapid, sensitive method for protein determination. FASEB. (Fed. Am. Soc. Exp. Biol.) J. $35: 274-274$

Brownlee, B. G., Hall, R. H., and Whitty, C. D. 1975. 3-Methyl-2-butenalEnzymatic degradation product of cytokinin, N6-(delta2-isopentenyl) adenine. Can. J. Biochem. 53:37-41.

Brzobohaty, B., Moore, I., Kristoffersen, P., Bako, L., Campos, N., Schell, J., and Palme, K. 1993. Release of active cytokinin by a beta-glucosidase localized to the maize root-meristem. Science 262:1051-1054.

Buchanan-Wollaston, V., Page, T., Harrison, E., Breeze, E., Lim, P. O., Nam, H. G., Lin, J. F., Wu, S. H., Swidzinski, J., Ishizaki, K., and Leaver, C. J. 2005. Comparative transcriptome analysis reveals significant differences in gene expression and signalling pathways between developmental and dark/starvation-induced senescence in Arabidopsis. Plant J. 42:567-585.

Calderini, O., Bovone, T., Scotti, C., Pupilli, F., Piano, E., and Arcioni, S. 2007. Delay of leaf senescence in Medicago sativa transformed with the IPT gene controlled by the senescence-specific promoter SAG12. Plant Cell Rep. 26:611-615.

Chen, L. F. O., Hwang, J. Y., Charng, Y. Y., Sun, C. W., and Yang, S. F 2001. Transformation of broccoli (Brassica oleracea var. italica) with isopentenyltransferase gene via Agrobacterium tumefaciens for postharvest yellowing retardation. Mol. Breed. 7:243-257.

Choi, J., Huh, S. U., Kojima, M., Sakakibara, H., Paek, K.-H., and Hwang, I. 2010. The cytokinin-activated transcription factor ARR2 promotes plant immunity via TGA3/NPR1-dependent salicylic acid signaling in Arabidopsis. Dev. Cell 19:284-295.

Choi, J., Choi, D., Lee, S., Ryu, C.-M., and Hwang, I. 2011. Cytokinins and plant immunity: Old foes or new friends? Trends Plant Sci. 16:388-394.

Clough, S. J., and Bent, A. F. 1998. Floral dip: A simplified method for Agrobacterium-mediated transformation of Arabidopsis thaliana. Plant J. 16:735-743.

Corsini, D. L., Thompson, C., and Pavek, J. J. 1989. The effect of plantgrowth regulators on verticillium wilt of potato. Am. Potato J. 66:125136.

D’Agostino, I. B., Deruere, J., and Kieber, J. J. 2000. Characterization of the response of the Arabidopsis response regulator gene family to cytokinin. Plant Physiol. 124:1706-1717.

De Michele, R., Vurro, E., Rigo, C., Costa, A., Elviri, L., Di Valentin, M. Careri, M., Zottini, M., di Toppi, L. S., and Lo Schiavo, F. 2009. Nitric oxide is involved in cadmium-induced programmed cell death in Arabidopsis suspension cultures. Plant Physiol. 150:217-228.

Dietrich, K., Weltmeier, F., Ehlert, A., Weiste, C., Stahl, M., Harter, K. and Droege-Laser, W. 2011. Heterodimers of the Arabidopsis transcription factors bZIP1 and bZIP53 reprogram amino acid metabolism during low energy stress. Plant Cell 23:381-395.

Eynck, C., Koopmann, B., Grunewaldt-Stoecker, G., Karlovsky, P., and von Tiedemann, A. 2007. Differential interactions of Verticillium longisporum and $V$. dahliae with Brassica napus detected with molecular and histological techniques. Eur. J. Plant Pathol. 118:259-274.

Falk, A., and Rask, L. 1995. Expression of a zeatin-o-glucoside-degrading beta-glucosidase in Brassica napus. Plant Physiol. 108:1369-1377.

Fradin, E. F., and Thomma, B. 2006. Physiology and molecular aspects of Verticillium wilt diseases caused by V. dahliae and V. albo-atrum. Mol. Plant Pathol. 7:71-86.

Frebortova, J., Fraaije, M. W., Galuszka, P., Sebela, M., Pec, P., Hrbac, J., Novak, O., Bilyeu, K. D., English, J. T., and Frebort, I. 2004. Catalytic reaction of cytokinin dehydrogenase: Preference for quinones as electron acceptors. Biochem. J. 380:121-130.

Gajdosova, S., Spichal, L., Kaminek, M., Hoyerova, K., Novak, O., Dobrev, P. I., Galuszka, P., Klima, P., Gaudinova, A., Zizkova, E., Hanus, J., Dancak, M., Travnicek, B., Pesek, B., Krupicka, M., Vankova, R., Strnad, M., and Motyka, V. 2011. Distribution, biological activities, metabolism, and the conceivable function of cis-zeatin-type cytokinins in plants. J. Exp. Bot. 62:2827-2840.

Galuszka, P., Popelkova, H., Werner, T., Frebortova, J., Pospisilova, H., Mik, V., Koellmer, I., Schmuelling, T., and Frebort, I. 2007. Biochemical characterization of cytokinin oxidases/dehydrogenases from Arabidopsis thaliana expressed in Nicotiana tabacum L. J. Plant Growth Regul. 26:255-267.

Gan, S. S., and Amasino, R. M. 1995. Inhibition of leaf senescence by autoregulated production of cytokinin. Science 270:1986-1988.

Gan, S. S., and Amasino, R. M. 1997. Making sense of senescenceMolecular genetic regulation and manipulation of leaf senescence. Plant Physiol. 113:313-319.

Grosskinsky, D.K., Naseem, M., Abdelmohsen, U. R., Plickert, N., Engelke, T., Griebel, T., Zeier, J., Novak, O., Strnad, M., Pfeifhofer, H., van der Graaff, E., Simon, U., and Roitsch, T. 2011. Cytokinins mediate resistance against Pseudomonas syringae in tobacco through increased antimicrobial phytoalexin synthesis independent of salicylic acid sig- naling. Plant Physiol. 157:815-830.

Hare, P. D., and Vanstaden, J. 1994. Cytokinin oxidase-Biochemical features and physiological significance. Physiol. Plant. 91:128-136.

Hothorn, T., Bretz, F., and Westfall, P. 2008. Simultaneous inference in general parametric models. Biometrical J. 50:346-363.

Hou, B. K., Lim, E. K., Higgins, G. S., and Bowles, D. J. 2004. N-glucosylation of cytokinins by glycosyltransferases of Arabidopsis thaliana. J. Biol. Chem. 279:47822-47832.

Huynh, L. N., VanToai, T., Streeter, J., and Banowetz, G. 2005. Regulation of flooding tolerance of SAG12:IPT Arabidopsis plants by cytokinin. J. Exp. Bot. 56:1397-1407.

Hwang, I., Sheen, J., and Müller, B. 2012. Cytokinin signaling networks. Annu. Rev. Plant Biol. 63:353-380.

Inderbitzin, P., Davis, R. M., Bostock, R. M., and Subbarao, K. V. 2011. The ascomycete Verticillium longisporum Is a hybrid and a plant pathogen with an expanded host range. PloS One 6. e18260. Published online.

Jameson, P. E. 2000. Cytokinins and auxins in plant-pathogen interactions-an overview. Plant Growth Regul. 32:369-380.

Jefferson, R. A., Kavanagh, T. A., and Bevan, M. W. 1987. GUS fusionsbeta-glucuronidase as a sensitive and versatile gene fusion marker in higher plants. EMBO (Eur. Mol. Biol. Organ.) J. 6:3901-3907.

Karapapa, V. K., Bainbridge, B. W., and Heale, J. B. 1997. Morphological and molecular characterization of Verticillium longisporum comb. nov., pathogenic to oilseed rape. Mycol. Res. 101:1281-1294.

Klosterman, S. J., Atallah, Z. K., Vallad, G. E., and Subbarao, K. V. 2009. Diversity, pathogenicity; and management of Verticillium species. Annu. Rev. Phytopathol. 47:39-62.

Kowalska, M., Galuszka, P., Frebortova, J., Sebela, M., Beres, T., Hluska, T., Smehilova, M., Bilyeu, K. D., and Frebort, I. 2010. Vacuolar and cytosolic cytokinin dehydrogenases of Arabidopsis thaliana: Heterologous expression, purification and properties. Phytochemistry 71:19701978

Kudryakova, N. V., Kusnetsov, V. V., Shtratnikova, V. Y., and Kulaeva, O. N. 2008. Effects of cytokinin and senescence-inducing factors on expression of $\mathrm{P}_{\mathrm{ARR} 5}$-GUS gene construct during leaf senescence in transgenic Arabidopsis thaliana plants. Plant Growth Regul. 56:21-30.

Lim, P. O., Kim, H. J., and Nam, H. G. 2007. Leaf senescence. Annu. Rev. Plant Biol. 58:115-136

Livak, K. J., and Schmittgen, T. D. 2001. Analysis of relative gene expression data using real-time quantitative PCR and the 2(T)(-Delta Delta C) method. Methods 25:402-408.

Miao, Y., Laun, T., Zimmermann, P., and Zentgraf, U. 2004. Targets of the WRKY53 transcription factor and its role during leaf senescence in Arabidopsis. Plant Mol. Biol. 55:853-867.

Misaghi, I., Kosuge, T., and Devay, J. E. 1972. Changes in cytokinin activity associated with development of Verticillium wilt and water stress in cotton plants. Physiol. Plant Pathol. 2:187-196.

Mok, D. W. S., and Mok, M. C. 2001. Cytokinin metabolism and action. Annu. Rev. Plant Physiol. Plant Mol. Biol. 52:89-118.

Murphy, A. M., PryceJones, E., Johnstone, K., and Ashby, A. M. 1997. Comparison of cytokinin production in vitro by Pyrenopeziza brassicae with other plant pathogens. Physiol. Mol. Plant Pathol. 50:53-65.

Noh, Y. S., and Amasino, R. M. 1999. Identification of a promoter region responsible for the senescence-specific expression of SAG12. Plant Mol. Biol. 41:181-194

Novak, O., Hauserova, E., Amakorova, P., Dolezal, K., and Strnad, M. 2008. Cytokinin profiling in plant tissues using ultra-performance liquid chromatography-electrospray tandem mass spectrometry. Phytochemistry 69:2214-2224

Paces, V., Werstiuk, E., and Hall, R. H. 1971. Conversion of N-6-(delta-2isopentenyl)adenosine to adenosine by enzyme activity in tobacco tissue. Plant Physiol. 48:775-778.

Patrick, T. W., Hall, R., and Fletcher, R. A. 1977. Cytokinin levels in healthy and Verticillium-infected tomato plants. Can. J. Bot. 55:377382.

Pegadaraju, V., Knepper, C., Reese, J., and Shah, J. 2005. Premature leaf senescence modulated by the Arabidopsis PHYTOALEXIN DEFICIENT4 gene is associated with defense against the phloem-feeding green peach aphid. Plant Physiol. 139:1927-1934.

Pegg, G. F., and Brady, B. L. 2002. Verticillium Wilts. CABI Publishing, Wallingford, U.K.

Pertry, I., Vaclavikova, K., Depuydt, S., Galuszka, P., Spichal, L., Temmerman, W., Stes, E., Schmuelling, T., Kakimoto, T., Van Montagu, M. C. E., Strnad, M., Holsters, M., Tarkowski, P., and Vereecke, D. 2009. Identification of Rhodococcus fascians cytokinins and their modus operandi to reshape the plant. Proc. Natl. Acad. Sci. U.S.A. 106:929-934.

Pertry, I., Vaclavikova, K., Gemrotova, M., Spichal, L., Galuszka, P., Depuydt, S., Temmerman, W., Stes, E., De Keyser, A., Riefler, M., 
Biondi, S., Novak, O., Schmuelling, T., Strnad, M., Tarkowski, P., Holsters, M., and Vereecke, D. 2010. Rhodococcus fascians impacts plant development through the dynamic Fas-mediated production of a cytokinin mix. Mol. Plant-Microbe Interact. 23:1164-1174.

Pinheiro, J., Bates, D., DebRoy, S. Sarkar, D., and the R Development Core Team 2013. nlme: Linear and Nonlinear Mixed Effects Models. R package version 3.1-108.

Pontier, D., Gan, S. S., Amasino, R. M., Roby, D., and Lam, E. 1999. Markers for hypersensitive response and senescence show distinct patterns of expression. Plant Mol. Biol. 39:1243-1255.

Popelkova, H., Fraaije, M. W., Novak, O., Frebortova, J., Bilyeu, K. D. and Frebort, I. 2006. Kinetic and chemical analyses of the cytokinin dehydrogenase-catalysed reaction: Correlations with the crystal structure. Biochem. J. 398:113-124

Ralhan, A., Schoettle, S., Thurow, C., Iven, T., Feussner, I., Polle, A., and Gatz, C. 2012. The vascular pathogen Verticillium longisporum requires a jasmonic acid-independent COI1 function in roots to elicit disease symptoms in Arabidopsis shoots. Plant Physiol. 159:1192-1203.

Richmond, A. E., and Lang, A. 1957. Effect of kinetin on protein content and survival of detached Xanthium leaves. Science 125:650-651.

Schmid, M., Davison, T. S., Henz, S. R., Pape, U. J., Demar, M., Vingron, M., Scholkopf, B., Weigel, D., and Lohmann, J. U. 2005. A gene expression map of Arabidopsis thaliana development. Nat. Genet. 37:501-506.

Schmülling, T., Werner, T., Riefler, M., Krupkova, E., and Manns, I. B. Y. 2003. Structure and function of cytokinin oxidase/dehydrogenase genes of maize, rice, Arabidopsis and other species. J. Plant Res. 116:241252

Snyder W. C., and Smith, S. N. 1981. Pages 25-50 in: Fungal Wilt Diseases of Plants. Academic Press, New York.

Spichal, L. 2012. Cytokinins-recent news and views of evolutionally old molecules. Funct. Plant Biol. 39:267-284.

Swartzberg, D., Kirshner, B., Rav-David, D., Elad, Y., and Granot, D. 2008. Botrytis cinerea induces senescence and is inhibited by autoregulated expression of the IPT gene. Eur. J. Plant Pathol. 120:289-297.

Sykorova, B., Kuresova, G., Daskalova, S., Trckova, M., Hoyerova, K., Raimanova, I., Motyka, V., Travnickova, A., Elliott, M. C., and Kaminek, M. 2008. Senescence-induced ectopic expression of the A. tumefaciens $I P T$ gene in wheat delays leaf senescence, increases cytokinin content, nitrate influx, and nitrate reductase activity, but does not affect grain yield. J. Exp. Bot. 59:377-387.
Thatcher, L. F., Manners, J. M., and Kazan, K. 2009. Fusarium oxysporum hijacks COI1-mediated jasmonate signaling to promote disease development in Arabidopsis. Plant J. 58:927-939.

van der Graaff, E., Schwacke, R., Schneider, A., Desimone, M., Fluegge, U.-I., and Kunze, R. 2006. Transcription analysis of Arabidopsis membrane transporters and hormone pathways during developmental and induced leaf senescence. Plant Physiol. 141:776-792.

Walters, D. R., and McRoberts, N. 2006. Plants and biotrophs: A pivotal role for cytokinins? Trends Plant Sci. 11:581-586.

Werner, T., Motyka, V., Strnad, M., and Schmülling, T. 2001. Regulation of plant growth by cytokinin. Proc. Natl. Acad. Sci. U.S.A. 98:1048710492.

Werner, T., Motyka, V., Laucou, V., Smets, R., Van Onckelen, H., and Schmülling, T. 2003. Cytokinin-deficient transgenic Arabidopsis plants show multiple developmental alterations indicating opposite functions of cytokinins in the regulation of shoot and root meristem activity. Plant Cell 15:2532-2550.

Whitty, C. D., and Hall, R. H. 1974. Cytokinin oxidase in Zea mays. Can. J. Biochem. 52:789-799.

Winter, D., Vinegar, B., Nahal, H., Ammar, R., Wilson, G. V., and Provart, N. J. 2007. An "electronic fluorescent pictograph" browser for exploring and analyzing large-scale biological data sets. PloS One 2:e718. Published online.

Xu, Y., Tian, J., Gianfagna, T., and Huang, B. 2009. Effects of SAG12-IPT expression on cytokinin production, growth and senescence of creeping bentgrass (Agrostis stolonifera L.) under heat stress. Plant Growth Regul. 57:281-291.

Yoshida, S. 2003. Molecular regulation of leaf senescence. Curr. Opin. Plant Biol. 6:79-84.

Zatloukal, M., Gemrotova, M., Dolezal, K., Havlicek, L., Spichal, L., and Strnad, M. 2008. Novel potent inhibitors of A. thaliana cytokinin oxidase/ dehydrogenase. Bioorg. Med. Chem. 16:9268-9275.

\section{AUTHOR-RECOMMENDED INTERNET RESOURCES}

Arabidopsis eFP browser: bar.utoronto.ca/efp

GraphPad QuickCalcs $t$ test: graphpad.com/quickcalcs/index.cfm

The R Project for Statistical Computing software: www.R-project.org Roche: www.roche-applied-science.com 